\title{
Analysis of the management of antipsychotics in a group of prisons
}

\author{
Hervás $\mathrm{G}^{1}$, Ruano $\mathrm{C}^{2}$, Sanz-Alfayate $\mathrm{G}^{3}$, Algora ${ }^{4}$, Celdran MA ${ }^{5}$, Mur MA
}

${ }^{1}$ Pharmacy Unit of Albolote Prison. Granada.

${ }^{2}$ Seville Prison Psychiatric Hospital.

${ }^{3}$ La Moraleja Prison. Palencia.

${ }^{4}$ Madrid III Prison.

${ }^{5}$ Alicante Prison Psychiatric Hospital.

${ }^{6}$ Zuera Prison. Zaragoza..

\begin{abstract}
Objective: To assess the use of prescribed antipsychotic treatments in the Spanish prison population in order to determine whether there are differences in efficacy and cost between the different long-acting antipsychotic injectables (LAIs).

Material and method: An observational, retrospective study was carried out in twelve prisons and in two prison psychiatric hospitals. To assess efficacy, all the clinical histories of patients with some kind of LAI were reviewed and only those who were in a situation of therapeutic stability were selected, defined as those treatments that had not undergone any change in the three last months, both in doses and in the association of another antipsychotic.

Results: Of the 11,953 inmates included in the study, 1,851 (15.5\%) received prescriptions for an antipsychotic, 415 in penitentiary psychiatric hospitals $(87 \%)$ and 1,436 in prisons $(12 \%)$, which is a much higher prevalence than that found in the population. Regarding the prescription pattern of LAIs, paliperidone is the most widely prescribed in prison psychiatric hospitals and prisons, followed by aripiprazole, zuclopenthixol and risperidone. Finally flufenazine, olanzapine and paliperidone quarterly, which are scarcely represented. Of the 292 patients with LAI, 41\% (121 patients) are with monotherapy and $59 \%$ (171 patients) are with polytherapy, which is similar to the data found in the bibliography.

Discussion: The use of prescribed LAIs amongst inmates is widespread. Polytherapy is also a common phenomenon, although there is a downward trend due to the use of more recently marketed drugs. Since the use of LAI is long-term, with numerous side effects and a wide range of prices, it is essential to consider the patient's risk factors and the cost of treatment alongside the therapeutic efficacy.
\end{abstract}

Keywords: schizophrenia, drug combinations, dosage forms, prisons.

Text received: 30/08/2018

Text accepted: 13/11/2018

\section{INTRODUCTION}

Schizophrenia is the most common psychotic disorder to be found amongst the non-affective psychotic syndromes contained in the DSM- 5 under the heading Schizophrenia and other psychotic disorders. Annual prevalence is $0.3 \%$ and annual incidence is 0.8 cases per 10,000 inhabitants, which means 4,000 new diagnosed cases of schizophrenia in Spain ${ }^{1}$.
The inmate population of the Spanish prison system was 51,602 in February 2017, according to figures published by the Spanish General Secretariat of Prisons (IIPP) $)^{2}$, which belongs to the Ministry of Home Affairs. $92.45 \%$ of said population are men and $7.55 \%$ are women. The inmates are located in different establishments, most of which are ordinary prisons, while there are two high security hospitals in Alicante and Seville. 
The World Health Organisation (WHO) estimates that in Western societies the incidence of psychiatric disorders is up to seven times higher in the prison population. Several studies have been carried out in Spain to establish the number and types of mental pathologies that exist in prisons. The results obtained show that $84.4 \%$ present some kind of mental disorder, while severe mental illnesses, most of which fall within the definition of psychosis, make up $4.2 \%$ of the cases $^{3-5}$. Drug dependence is also a major destabilising factor in this population. It is estimated that $76 \%$ of the inmates consumed drugs in the month prior to entering prison ${ }^{6}$.

For healthcare, the Spanish inmate population depends on the General Subdirectorate for Coordination of Prison Healthcare, which in turn answers to the General Secretariat of Prisons, in accordance with Organic Law 1/1979 and Royal Decree 190/1996, with the exception of the communities of Catalonia and the Basque Country, where the prison healthcare powers have been transferred to the Health Departments of their Autonomous Governments. The range of healthcare options available within the network of the General Secretariat of Prisons for persons suffering from some kind of psychiatric illness includes:

- Intervention by psychiatrists, who are staff members at the high security hospitals, or consultants at the other prisons.

- Dispensation of prescribed medication.

- Development of specific programs, such as the Comprehensive healthcare program for mentally ill patients (PAIEM in Spanish).

Given the high prevalence of mental illness, the use of antipsychotics in the prison milieu is widely extended. In recent years there has been an increase in the use of long-acting antipsychotic injectables (LAI), in parallel with the increased use of this therapy outside prison ${ }^{7,8}$. However, no differences in efficacy between the oral and injected formulations have been observed ${ }^{9}$. Treatments with LAIs frequently include the use of more than antipsychotic drug ${ }^{10-12}$ (some studies report up to $75.9 \%$ of antipsychotic polytherapy), although most clinical guides do not recommend the simultaneous use of more than one antipsychotic because of the risk of increased adverse effects and of pharmaco-kinetic interactions ${ }^{13}$. The appearance of adverse effects (extrapyramidal reactions, weight gain, etc.) may lead to non-compliance with treatment ${ }^{14}$ and sometimes cause subsequent use of doses higher than the ones recommended in the summary of product characteristics ${ }^{15}$.

The objective of this study is to evaluate the prevalence of antipsychotic treatments in the Spanish prison population, establish if there are differences in terms of efficacy and the financial costs of the LAIs used in prisons managed by the General Secretariat of Prisons, and determine to what extent doses higher than the ones established in the summary of product characteristics are prescribed for each antipsychotic drug included in the study.

\section{MATERIALS AND METHODS}

An observational, retrospective study was carried out at twelve prisons and two high security psychiatric hospitals. No interviews with patients or interventions that altered the prescription or dispensation of drugs were required. The data was gathered in the first week of March 2017, in unlinked form to ensure the confidentiality of the data.

Each participating centre was sent a table, containing the names of the participating centres and the total number ( $\mathrm{n}$ ) of inmates present at the time the study commenced. The clinical histories were reviewed, in order to find out the number of inmates receiving some kind of prescribed antipsychotic treatment. The clinical histories were also consulted only those that complied with the condition of antipsychotic therapeutic stability were selected. This criterion was defined as a "stable LAI regimen, at a fixed dose, for a minimum of three months".

The following information about the patients was gathered: a) anonymous identification of the patient; b) prison; c) gender; d) age (in years); e) psychiatric diagnosis; f) LAI drug(s) prescribed, indicating the dose and frequency of administration.

For antipsychotic polytherapy, data about the concomitantly prescribed oral and injectable antipsychotics was gathered, indicating the daily dose. The drugs regarded as antipsychotics are those included in group N05A of the Anatomical Therapeutic Chemical Classification (ATC). An antipsychotics monotherapy is regarded as such when only one LAI was recommended, and polytherapy was considered to be treatment that consisted of an LAI and another prescribed concomitant oral or injectable antipsychotic. As regards the doses, the summaries of product characteristics were consulted and the following maximum doses for the LAIs included in the study were extracted: aripiprazol $=400 \mathrm{mg} / 28$ days, flufenazine $=100 \mathrm{mg} / 28$ day, olanzapine $=405 \mathrm{mg} / 28$ days, monthly paliperidone $=150 \mathrm{mg} / 28$ days, paliperidone quarterly $=525 \mathrm{mg} / 90$ days, risperidone $=50 \mathrm{mg} / 14$ days and zuclopentixol $=200 \mathrm{mg} / 14$ days. When the summary of product characteristics stated that admi- 
nistration is monthly, it was included in four weeks (28 days). Regimens with doses over the maximum stated in the summary of product characteristics in an interval equal to or less than the one recommended were regarded as over-dosages. The prices of the LAIs were also gathered from the laboratory lists and the ex-factory prices (EFP) without VAT were included for assessment purposes.

All the data collected from each centre was grouped onto a common Excel spreadsheet for subsequent appraisal and application of the statistical study. The data is presented as means \pm SEM (standard error of the mean) of the values obtained in the data collection, and the significance of the differences observed was calculated with the Student two-tailed unpaired t test. The ANOVA variance analysis was used for comparisons of means of multiple groups. The data was considered to be statistically significant when the value of "p" was less than 0.05 .

The corresponding authorisation mandatory for this area of research in prisons was requested. The authorisation was granted in December 2016 the general assistant secretary of Institutional Relations and Territorial Coordination of the General Secretariat of Prisons, which forms part of the Ministry of Home Affairs.

\section{RESULTS}

1,851 inmates were prescribed an antipsychotic $(87.36 \%$ of the inmates of the high security hospitals and $12 \%$ of prison inmates) and 340 received an LAI as part of their treatment. After excluding those who did not comply with the criterion of antipsychotic therapeutic stability, the population was reduced to 292 patients. Of these, 275 were man with a mean age of 42 years and 17 were women with a mean age of 43 years (Table 1 ).

The diagnoses showed that 181 presented schizophrenia, and 52 had other psychotic disorders (25 diagnosed with secondary psychotic disorder from substance consumption). 39 cases were diagnosed with personality disorder, four with impulse control disorder, three with bipolar disorder, two with intellectual disability, one with Gilles de la Tourette syndrome, one with severe depression and psychotic symptoms and one with agitation.

The prescription pattern showed that paliperidone was the most commonly prescribed antipsychotic $(50 \%)$, followed by aripiprazol, zuclopentixol and risperidone, in very similar percentages, which were approximately $14 \%$. Flufenazine and olanzapine were only prescribed for $3 \%$, and quarterly paliperidone for $1 \%$. However, the last of these drugs was placed on the market in 2016, which made the option of prescribing it a difficult process (Table 2 and Figure 1).

The level of association between LAI and other antipsychotics showed that $191(41 \%)$ were receiving mono-therapy and $171(59 \%)$ were undergoing polytherapy. Only two LAIs were associated with two, and an injectable antipsychotic was associated with an oral one. 19\% had been prescribed oral antipsychotics, and in one case, three oral drugs. Figure 2 shows the percentages of antipsychotics in monotherapy compared to polytherapy and the statistical association.

As regards oral antipsychotics associated with an LAI, olanzapine and quetiapine were the most frequently used combination $37 \%$ and $31 \%$ of the cases of polytherapy, respectively) and haloperidol, amisulpride and paliperidone were the ones least combined (percentages below 3\%). Other antipsychotics (aripiprazol, clozapine, clotiapine, levomepromazine and risperidone) were combined in $13 \%, 10.5 \%, 10 \%$, $6.5 \%$ and $6 \%$, respectively.

$83.6 \%$ of the prescribed treatments $(n=244)$ were within the therapeutic range, and $16.4 \%$ at doses above this range (Figures 3 and 4). The result, broken down into each drug, is as follows:

- In prisons and high security hospitals, the prescriptions of aripiprazol (97.72 \pm 2.38 and 88.62 \pm 3.32 , respectively), flufenazine $(38.33 \pm 8.12$ and $35, .99 \pm 6.7$, respectively) and zuclopentixol $(76.32 \pm 8.11$ and $89.12 \pm 9.42$, respectively) were within the therapeutic range interval.

- In prisons and high security hospitals, the prescriptions of paliperidone were also within the therapeutic range $(17.37 \pm 3.43$ and $93.06 \pm$ 3.97, respectively), but with statistically significant differences between both types of centers $(\mathrm{p}<0.05)$.

- In prisons and high security hospitals, the prescriptions of risperidone (93.42 \pm 9.38 and 116.66 \pm 9.24 , respectively) were made above the dose recommended in the summary of product characteristics.

As regards the financial cost, the mean cost per LAI and patient was 252.8 euros/28 days (Table 3 ). There is a highly variable interval, between those of higher cost, which correspond to the ones recently marketed, and the others. Thus, the cost of paliperidone is 338.92 euros, while the cheapest one, flufenazine, is 3.06 euros. 
Table 1. Inmates/patients included in the study

\begin{tabular}{|c|c|c|c|c|}
\hline Prison or hospital & $\mathrm{N}^{\mathrm{o}}$ inmates & $\begin{array}{l}\text { Patients with } \\
\text { antipsychotics* }\end{array}$ & $\begin{array}{l}\text { Patients with LAI } \\
\text { Total LAI/Stable LAI }\end{array}$ & $\begin{array}{l}\text { \% Total patients with LAI } \\
\text { compared to patients with } \\
\text { prision antipsychotics }\end{array}$ \\
\hline Alicante High Sec. Hosp & 289 & $264(91.3 \%)$ & $113 / 113$ & $42.8 \%$ \\
\hline Seville High Sec. Hosp & 186 & $151(81.2 \%)$ & $72 / 56$ & $47.7 \%$ \\
\hline Subtotal Hospitals & 475 & $415(87.4 \%)$ & $185 / 169$ & $44.6 \%$ \\
\hline Albolote & 1299 & $140(10.8 \%)$ & $36 / 32$ & $25.7 \%$ \\
\hline Alicante sentence & 728 & $24(3.3 \%)$ & $7 / 6$ & $29.2 \%$ \\
\hline Córdoba & 1265 & $127(10.0 \%)$ & $19 / 19$ & $15.0 \%$ \\
\hline El Dueso & 453 & $88(19.4 \%)$ & $7 / 3$ & $7.9 \%$ \\
\hline La Moraleja & 953 & $240(25.2 \%)$ & $14 / 7$ & $5.8 \%$ \\
\hline Madrid III-Valdemoro & 1037 & $74(7.1 \%)$ & $11 / 11$ & $14.9 \%$ \\
\hline Madrid IV-Navalcarnero & 1089 & $185(17.0 \%)$ & $12 / 7$ & $6.5 \%$ \\
\hline Madrid V-Soto del Real & 1333 & $81(6.1)$ & $5 / 3$ & $6.2 \%$ \\
\hline Málaga & 1188 & $107(9.0 \%)$ & $12 / 10$ & $11.2 \%$ \\
\hline Pamplona I & 271 & $56(20.7 \%)$ & $6 / 4$ & $10.7 \%$ \\
\hline Valladolid & 500 & $55(11.0 \%)$ & $4 / 2$ & $7.3 \%$ \\
\hline Zaragoza & 1362 & $259(19.0 \%)$ & $22 / 19$ & $8.5 \%$ \\
\hline Subtotal Prisons & 11478 & $1436(12.5 \%)$ & $155 / 123$ & $10.8 \%$ \\
\hline Total hospitals + prisons & 11953 & $1851(15.5 \%)$ & $340 / 292$ & $18.4 \%$ \\
\hline
\end{tabular}

Note. "Patients with antipsychotics: \% regarding the population of the prison.

Table 2. Distribution of LAI prescriptions in two hospitals and in prisons

\begin{tabular}{|c|c|c|c|c|}
\hline & Hospitals & Prisons & $\%$ Hospitals & $\%$ Prisons \\
\hline Aripiprazol & 31 & 11 & 18 & 8.9 \\
\hline Flufenazine & 5 & 5 & 3 & 4.1 \\
\hline Olanzapine & 8 & 1 & 4.7 & 0.8 \\
\hline Paliperidone & 82 & 64 & 48 & 52 \\
\hline Risperidone & 22 & 19 & 13 & 15.5 \\
\hline Zuclopentixol & 19 & 22 & 11.2 & 18 \\
\hline Palip quarterly & 2 & 1 & 1.2 & 0.8 \\
\hline Total & 169 & 123 & & \\
\hline
\end{tabular}

\section{DISCUSSION}

There is a high prevalence of pathology in the prison environment ${ }^{2}$. Furthermore, the unfavourable environment, the lack of awareness in some cases of the illness and the possible fear of patients of being stigmatised as someone who is mentally ill, may have a lot to do with low adherence to treatment. Therefore, the use of LAIs may be a very attractive option for prisons and high security hospitals to ensure patient adherence.
New LAIs have recently been put onto the market (aripiprazol, olanzapine and paliperidone), at a cost way above that of antipsychotics already on sale, which puts into question if the efficacy/economic cost quotient really implies a benefit for the health system.

The idiosyncrasies of the prison environment, where patients feel a certain degree of fear about being affected by regulatory measures and where there are considerations of an ethical nature that complicate the processes involved in experimental studies, have played part in the decision to carry out an observational study. There 


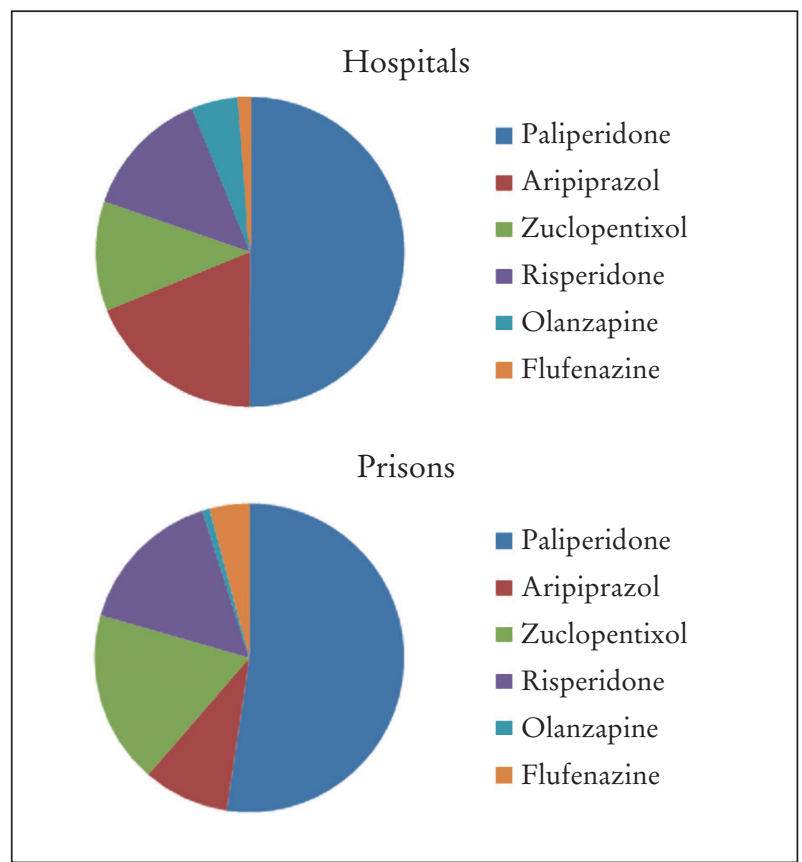

Figure 1. Graph of antipsychotic drug distribution.

is a higher probability of bias in this type of study, but it does avoid the use of standardised scales and enables work to be done with a very numerous patient sample.

The results show that the LAI recently included in the Medical Drug Guide, such as aripiprazol and paliperidone, and to a lesser extent other drugs such as olanzapine, zuclopenxitol, risperidone and flufenazine require less frequent association with other antipsychotics to stabilise the patient.

The rate of antipsychotic prescription in Spanish prisons is in the range (4-70\%) shown in scientific publications, depending on the place and population studied ${ }^{16}$.

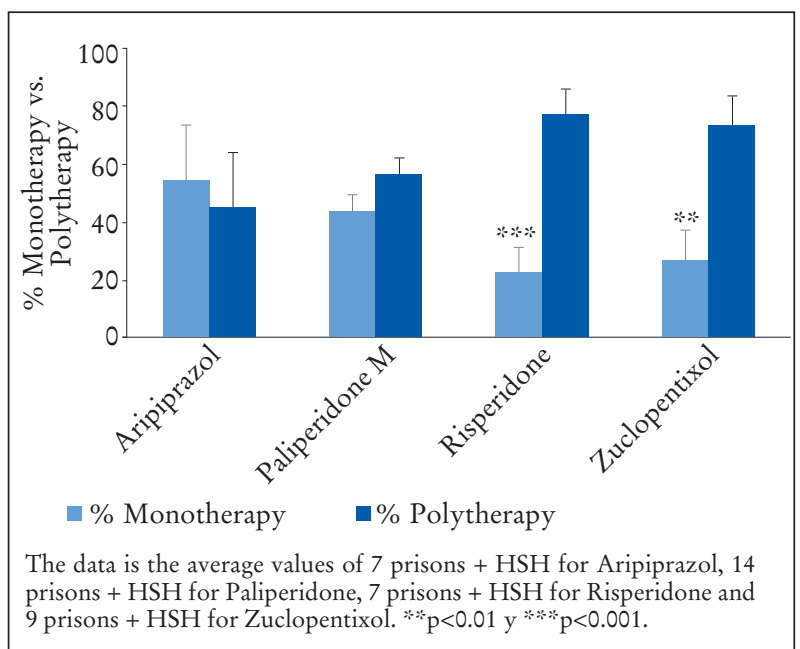

Figure 2. Percentages of monotherapy versus polytherapy .

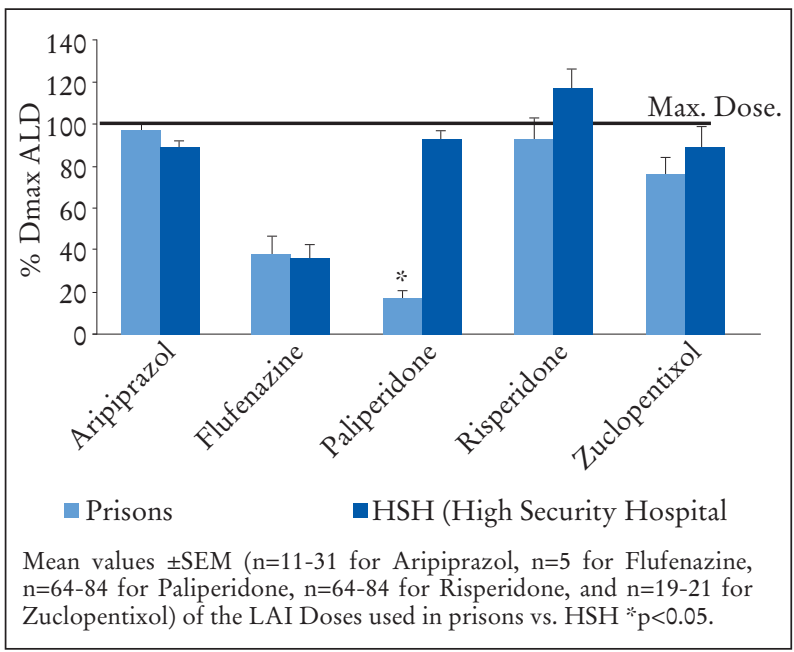

Figure 3. Ratio of patients treated with LAI in prisons and high security hospitals.

\begin{tabular}{|c|c|c|c|c|}
\hline \multicolumn{5}{|c|}{ Table of doses in SPC vs. overdose } \\
\hline ALD & Dose within SPC & Dose over SPC & Dose within SPC & Dose over SPC \\
\hline Aripiprazol & 42 & 0 & 100 & 0 \\
\hline Flufenazine & 10 & 0 & 100 & 0 \\
\hline Olanzapine & 3 & 6 & 33 & 67 \\
\hline Paliperidone & 118 & 28 & 81 & 19 \\
\hline Paliperidone Quarterly & 3 & 0 & 100 & 0 \\
\hline Risperidone & 32 & 9 & 78 & 22 \\
\hline Zuclopentixol & 36 & 5 & 88 & 12 \\
\hline
\end{tabular}

Figure 4. Prescriptions out of range compared to total number of prescriptions per drug. 
Olanzapine and quetiapine stand out amongst the prescribed oral antipsychotics associated with LAIs, probably because of their greater sedative capacity, which is highly beneficial for some patients. In the case of olanzapine, this may also be due to the search for a synergistic effect in the mechanism of action of the associated drugs.

As regards the cost of treatments, only the direct costs have been taken into account, and it was found

Table 3. Study of measured expenditure according to drug used

Coste de todos los centros penitenciarios

Cost for all prisons

\begin{tabular}{|c|c|}
\hline $\begin{array}{l}\text { Average cost a year of all LAIS per stable } \\
\text { patient }\end{array}$ & $3.286,43 €$ \\
\hline Reported average cost at 28 days & $252,80 €$ \\
\hline Patients & 292 \\
\hline \multicolumn{2}{|l|}{ LAI } \\
\hline \multicolumn{2}{|l|}{ Average cost per year of ariprazol } \\
\hline Per stable patient & $2.982,75 €$ \\
\hline Reported average cost at 28 days & $229,44 €$ \\
\hline Patients & 42 \\
\hline \multicolumn{2}{|l|}{ Average cost per year of flufenazine } \\
\hline Per stable patient & $39,81 €$ \\
\hline Reported average cost at 28 days & $3,06 €$ \\
\hline Patients & 10 \\
\hline \multicolumn{2}{|l|}{ Average cost per year of olanzapine monthly } \\
\hline Per stable patient & $4.302,84 €$ \\
\hline Reported average cost at 28 days & $330,99 €$ \\
\hline Patients & 9 \\
\hline \multicolumn{2}{|l|}{ Average cost per year of paliperidone } \\
\hline Per stable patient & $4.405,96 €$ \\
\hline Reported average cost at 28 days & $338,92 €$ \\
\hline Patients & 146 \\
\hline \multicolumn{2}{|c|}{ Average cost per year of paliperidone quarterly } \\
\hline Per stable patient & $2.698,59 €$ \\
\hline Reported average cost at 28 days & $207,58 €$ \\
\hline Patients & 3 \\
\hline \multicolumn{2}{|l|}{ Average cost per year of risperidone } \\
\hline Per stable patient & $3.411,76 €$ \\
\hline Reported average cost at 28 days & $262,44 €$ \\
\hline Patients & 41 \\
\hline \multicolumn{2}{|l|}{ Average cost per year of zuclopentixol } \\
\hline Per stable patient & $97,31 €$ \\
\hline Reported average cost at 28 days & $7,49 €$ \\
\hline Patients & 41 \\
\hline
\end{tabular}

that there were major differences between them. Zuclopentixol and flufenazine are the most economical options compared to aripiprazol, risperidone, olanzapine and paliperidone, in decreasing order.

The conclusion can be drawn that: aripiprazol and monthly paliperidone present the best results in accordance with the measured variable, which is the level of prescription in monotherapy. Aripiprazol works at a lower cost than monthly paliperidone. Zuclopentixol did not achieve good results, with $27.16 \%$ of co-prescriptions with oral antipsychotics. Its use may well be restricted by its potential advantages, which are: flexibility of dosage and frequency compared to the new LAIs and low cost.

Considering that this groups of medicines has a large number of adverse effects, especially effects on the metabolism and extrapyramidal symptoms, and that they are drugs that the patient is going to take for a long time, it is essential to avoid redundancy in prescribing antipsychotics. In this regard, aripiprazol and paliperidone have shown themselves to be superior in comparison to the other LAIs in the study.

\section{CONCLUSIONS}

- Antipsychotic polytherapy is widely used in this environment. Given the large number of side effects and interactions with other treatments, efforts should be made to establish measures that promote the prescription of monotherapy.

- The percentage of LAIs prescribed as antipsychotic treatment is less in prisons than in high security hospitals.

- The LAI most recently included in the Medical Drug Guide, aripiprazol and paliperidone, have shown better results in terms of stabilising patients under a regime of prescribed monotherapy.

- The LAI that is most frequently used above the maximum in the therapeutic range of the summary of product characteristics is risperidone, and this tends to take place more frequently in high security hospitals than in prisons.

- Given that there is a major difference in cost between the different treatments studied, it should be another factor to bear in mind when selecting the most adequate therapeutic option.

\section{ACKNOWLEDGEMENTS}

We would like to thank the following colleagues for their participation in collecting the data at their 
centres: Maria Rosario Fernández Pérez, pharmacist at the El Dueso prison; Calos Huertas Rivas, specialist pharmacist at the Madrid IV prison; Marta Monedero Ramos, specialist pharmacist at the Madrid V prison; Carmen Salinas Rosillo, specialist pharmacist at the Malaga prison; and Maria Luisa Martinez de Lecea Placer, specialist pharmacist at Pamplona prison, for their contributions both in collecting the data and analysing the work.

We are also very grateful for the collaboration of Iván Fernández-Bobadilla, higher technician of Specific Activities at the High Security Hospital of Seville, for his assistance in unifying the data compiled from the prisons in one single table and for preparing the resulting reports, which we were able to use as a basis for our results.

\section{CORRESPONDENCE}

Gloria Maria Hervas Leyva

Pharmacy Unit of Albolote Prison (Granada).

E-mail: gloria.hervas@dgip.mir.es

\section{REFERENCES}

1. Crespo-Facorro B, Bernardo M, Argimon JM, Arrojo M, Bravo-Ortiz MF, Cabrera-Cifuentes A, et al. Eficacia, eficiencia y efectividad en el tratamiento multidimensional de la esquizofrenia: proyecto Rethinking. Rev Psiquiatr Salud Ment. 2107;10:4-20.

2. Estadística penitenciaria. [Internet]. En: Secretaria General de Instituciones Penitenciarias. Ministerio del Interior; 2017. Disponible en: http:// www.institucionpenitenciaria.es/web/portal/documentos/estadisticas.html

3. Vicens E, Tort V, Dueñas RM, Muro Á, Pérez-Arnau F, Arroyo JM, et al. The prevalence of mental disorders in Spanish prisons. Crim Behav Ment Health. 2011;21:321-32.

4. Zabala-Baños MC, Segura A, Maestre-Miquel C, Martínez-Lorca M, Rodríguez-Martín B, Romero D, et al. Prevalencia de trastorno mental y factores de riesgo asociados en tres prisiones de España. Rev Esp Sanid Penit. 2016;18:13-24.

5. Estudio sobre salud mental en el medio penitenciario. Dirección General de Instituciones Penitenciarias. Secretaría General de Sanidad Penitenciaria; 2006.

6. Informe General 2016. [Internet]. Secretaría General de Instituciones Penitenciarias. Ministerio del Interior. 2017. Disponible en: http://www. institucionpenitenciaria.es/web/portal/documentos/publicaciones.html

7. Doshi JA, Pettit AR, Stoddard JJ, Zummo J, Marcus SC. Concurrent Oral Antipsychotic Drug Use Among Schizophrenia Patients Initiated on Long-Acting Injectable Antipsychotic PostHospital Discharge. J Clin Psychopharmacol. 2015;35:442-6.

8. Aggarwal NK, Sernyak MJ, Rosenheck RA. Prevalence of Concomitant Oral Antipsychotic Drug Use Among Patients Treated With Long-Acting, Intramuscular, Antipsychotic Medications. J Clin Psychopharmacol. 2012;32:323-8.

9. Leucht S, Cipriani A, Spineli L, Mavridis D, Orey $\mathrm{D}$, Richter $\mathrm{F}$, et al. Comparative Efficacy and Tolerability of 15 Antipsychotic Drugs in Schizophrenia: a Multiple-treatments Meta-analysis. Lancet. 2013;382:951-62.

10. Toteja N, Gallego JA, Saito E, Gerhard T, Winterstein A, Olfson M, et al. Prevalence and Correlates of Antipsychotic Polypharmacy in Children and Adolescents Receiving Antipsychotic Treatment. Int J Neuropsychopharmacol. 2014;17:1095-105.

11. Faries D, Ascher-Svanum H, Zhu B, Correll C, Kane J. Antipsychotic Monotherapy and Polypharmacy in the Naturalistic Treatment of Schizophrenia with Atypical Antipsychotics. BMC Psychiatry. 2005;5:26.

12. Bernardo M, Coma A, Ibáñez C, Zara C, Bari JM, Serrano-Blanco A. Antipsychotic Polypharmacy in a Regional Health Service: a Population-Based Study. BMC Psychiatry. 2012;12:42.

13. Guía de Práctica Clínica Sobre la Esquizofrenia y el Trastorno Psicótico Incipiente. [Internet]. Sistema Nacional de Salud. Ministerio de Sanidad y Consumo; 2009. p. 67-73. Disponible en: http:// www.guiasalud.es/GPC/GPC_495_Esquizofr_ compl_cast_2009.pdf

14. Gila Azañedo JA, Chamorro García L. Efectos adversos asociados al tratamiento con antipsicóticos atípicos. Bolentín Farmacoterapétuico de Castilla-La Mancha. 2004;2:1-4.

15. Procyshyn RM, Honer WG, Wu TK, Ko RW, McIsaac SA, Young AH, et al. Persistent antipsychotic polypharmacy and excessive dosing in the community psychiatric treatment setting: a review of medication profiles in 435 Canadian outpatients. J Clin Psychiatry. 2010;71:566-73.

16. Fleischhacker WW, Uchida H. Critical review of antipsychotic polypharmacy in the treatment of schizophrenia. Int J Neuropsychopharmacol. 2014;17:1083-93. 